\title{
DETERMINAN LOKASI SENTRA INDUSTRI KERAJINAN BAMBU DI KABUPATEN SLEMAN
}

\section{DETERMINANT OF THE LOCATION OF THE CENTER OF BAMBOO INDUSTRY IN SLEMAN REGENCY}

\author{
Dellamanda Yosky', Sri Rahayu Budiani² \\ ${ }^{1}$ Fakultas Geografi UGM; Sekip Utara, Bulak Sumur, Yogyakarta 55281; dellamanda.yosky@gmail.com \\ ${ }^{2}$ Fakultas Geografi UGM; Sekip Utara, Bulak Sumur, Yogyakarta 55281; srahayu@ugm.ac.id
}

Info Artikel:

- Artikel Masuk: 7 Oktober 2018

- Artikel diterima: 22 November 2019

- TersediaOnline: 31 Desember 2019

\begin{abstract}
ABSTRAK
Industri Kecil dan Menengah Kabupaten Sleman cabang industri kerajinan didominasi oleh industri kerajinan bambu. Industri ini membentuk sentra-sentra di wilayah tertentu yang menghasilkan produk khas. Lokasi merupakan hal penting dalam industri karena berhubungan dengan efisiensi produksi dan pemasaran. Tujuan dari penelitian ini adalah mengetahui distribusi, karakteristik, serta faktor yang paling berpengaruh teerhadap pemilihan lokasi sentra industri kerajinan bambu di Kabupaten SlemanPenelitian ini dilakukan secara survei. Pengambilan sampel ditentukan secara acak di masing-masing sentra dengan metode Proporsionate Stratified Random Sampling. Total responden sebanyak 87 unit usaha. Analisis dilakukan dengan hasil berupa peta, tabel frekuensi, serta analisis kuantitatif regresi linier berganda. Hasil penelitian menunjukkan bahwa 1) Lokasi sentra-sentra industri kerajinan bambu Kabupaten Sleman cenderung mengelompok di wilayah Kabupaten Sleman bagian barat dengan masing-masing sentra memiliki produk khas. 2) Industri kerajinan bambu Kabupaten Sleman didominasi oleh industri skala rumah tangga. 3) Faktor yang yang paling berpengaruh terhadap keuntungan sebagai fungsi karakteristik spesifik lokasi industri kerajinan bambu Kabupaten Sleman adalah kuantitas bahan baku.
\end{abstract}

Kata Kunci: lokasi, sentra, industri kerajinan bambu, karakteristik, pengaruh.

\section{ABSTRACT}

Small and Medium Industries in Sleman Regency, the branch of handicraft industry is dominated by the bamboo industry. This industry forms centers in certain regions. Location is an important thing because it's related to the efficiency of the industrial production and marketing. The purposes of this study are: 1) Knowing the distribution, characteristics, and the most influential factors in choosing the location of the center of the bamboo industry in Sleman Regency. This research used survey method. Sampling is taken randomly in each center using the Proportionate Stratified Random Sampling method. Total respondents are 87. The analysis is carried out with the results in the form of maps, frequency tables and quantitative analysis of multiple linear regression. The results showed that 1) The locations of the centers of the bamboo industry in Sleman Regency tended to be in the west region of Sleman Regency with each center having distinctive products. 2) The bamboo industry in Sleman Regency is dominated by household scale industries. 3) Factor that have the most influence on profits as a function of the specific characteristics of the location of the bamboo industry in Sleman Regency is the quantity of raw material.

Keyword: location, center, bamboo industry, caracteristic, determinant. 


\section{PENDAHULUAN}

Industri kerajinan merupakan cabang Industri Kecil dan Menengah (IKM) yang paling banyak terdapat di Kabupaten Sleman, Daerah Istimewa Yogyakarta. Industri kerajinan di Kabupaten Sleman didominasi oleh industri kerajinan bambu. Bambu sebagai bahan baku industri ini telah ditetapkan sebagai Hasil Hutan Bukan Kayu (HHBK) Unggulan di Kabupaten Sleman oleh pemerintah melalui SK Bupati Sleman No. 306/Kep.KDH/A/2013.

Data BPS tahun 2016 menunjukkan jumlah tanaman bambu di Kabupaten Sleman paling banyak berada di Kecamatan Pakem yaitu sebanyak 5.468.550 rumpun. Kecamatan Cangkringan berada di posisi kedua dengan jumlah tanaman bambu sebanyak 1.371 .080 rumpun. Namun demikian, sentra industri kerajinan bambu di Kabupaten Sleman terletak di kecamatan yang berbeda.

Data Dinas Perindustrian dan Perdagangan DIY tahun 2017 menunjukkan terdapat lima kecamatan yang memiliki sentra industri kerajinan bambu yaitu Kecamatan Minggir, Moyudan, Godean, Seyegan, dan Mlati. Berdasarkan karakteristik wilayahnya di Kabupaten Sleman, Kecamatan Minggir, Moyudan, Godean, dan Seyegan termasuk dalam kategori wilayah barat yang merupakan daerah pertanian lahan basah dan sumber bahan baku kegiatan industri kerajinan mendong, bambu, serta gerabah sedangkan Kecamatan Mlati termasuk dalam kategori wilayah tengah yaitu wilayah aglomerasi Kota Yogyakarta.

Lokasi merupakan salah satu faktor penting dalam suatu industri. Hal ini terkait dengan efektivitas dan efisiensi untuk mendapatkan bahan baku, menjalankan produksi, maupun memasarkan hasil produksi. Sentra industri kerajinan bambu di Kabupaten Sleman sebagian besar terdapat di wilayah bagian barat. Hal tersebut tentu saja dipengaruhi oleh faktor-faktor lokasi yang menyebabkan terbentuknya sentra industri kerajinan bambu di wilayah-wilayah tersebut.

Faktor-faktor lokasi dapat memiliki tingkat pengaruh yang sama maupun bervariasi terhadap pemilihan lokasi industri. Besar pengaruh masing-masing faktor lokasi terhadap pemilihan lokasi industri kerajinan bambu di Kabupaten Sleman juga perlu untuk diteliti. Hal tersebut bertujuan untuk mengetahui faktor yang paling dominan mempengaruhi sehingga nantinya pengembangan industri ini dapat lebih optimal. Tujuan penelitian ini diantaranya :

1. Mengetahui distribusi sentra industri kerajinan bambu di Kabupaten Sleman.

2. Mengetahui karakteristik usaha industri kerajinan bambu di Kabupaten Sleman.

3. Mengetahui faktor yang paling berpengaruh terhadap pemilihan lokasi sentra industri kerajinan bambu di Kabupaten Sleman.

Beberapa teori lokasi yang menjadi dasar dalam penelitian ini diantaranya teori Weber dalam Bale (1981) menjelaskan bahwa faktor produksi mempengaruhi pemilihan lokasi. Faktor produksi tersebut seperti biaya transportasi, biaya tenaga kerja, serta aglomerasi dan deglomerasi.

Teori lainnya yaitu Teori Lösch (1954) menjelaskan lokasi optimal suatu pabrik atau industri adalah ketika industri dapat menguasai wilayah pasaran yang terluas. Smith dalam Muzayanah (2015) menjelaskan mengenai pemilihan lokasi industri berdasar pada keuntungan maksimal. Keuntungan maksimal dapat diperoleh dengan memperhatikan efisiensi faktor produksi serta kaitannya dengan pasar. Dalam penelitian ini, faktor pemilihan lokasi yang digunakan adalah kedekatan bahan baku, kuantitas bahan baku, upah tenaga kerja, dan kedekatan pasar.

\section{METODE PENELITIAN}

Penelitian ini dilakukan dengan metode survei dan juga merupakan penelitian kuantitatif. Populasi dalam penelitian ini adalah pelaku usaha industri kerajinan bambu di Kabupaten Sleman. Jumlah pelaku usaha dapat dilihat berdasarkan jumlah unit usaha industri kerajinan bambu di Kabupaten Sleman. Metode penentuan jumlah total responden dilakukan dengan Metode Slovin, yaitu dengan rumus sebagai berikut. (Sugiyono, 2011) 
Keterangan :

$$
n=\frac{N}{N \cdot e^{2}+1}
$$

$\mathrm{n}=$ jumlah sampel

$\mathrm{N}=$ jumlah populasi

e = persentase kelonggaran ketelitian kesalahan pengambilan sampel yang masih bisa ditolerir, e = 0,1

Jumlah unit usaha industri kerajinan bambu terdaftar dan terverifikasi di lapangan di Kabupaten Sleman sejumlah 653 unit usaha. Berdasarkan rumus perhitungan pengambilan sampel Slovin dapat diketahui jumlah sampel adalah sebagai berikut.

$$
\begin{gathered}
n=\frac{653}{653 \cdot(0,1)^{2}+1}=86,72 \\
n=86,72 \text {, dibulatkan menjadi } 87 \text { sampel }
\end{gathered}
$$

Penentuan jumlah sampel responden masing-masing sentra dilakukan dengan metode Proporsionate Random Sampling, hal ini dilakukan agar tiap-tiap sentra dapat terwakili dengan jumlah sampel responden sesuai dengan jumlah unit usaha industri. Cara pengambilan sampel tiap-tiap sentra dilakukan dengan Simple Random Sampling.

Penelitian ini menggunakan data primer dan sekunder. Penelitian dilakukan dengan mengumpulkan data-data sekunder dari instansi terkait yang diperlukan, melakukan observasi di lapangan, mengambil titik plot sentra, serta melakukan wawancara terstruktur kepada responden.

Analisis peta persebaran sentra industri kerajinan bambu dilakukan secara deskriptif. Analisis karakteristik usaha industri dilakukan dengan analisis deskriptif-kuantitatif dengan tabel frekuensi. Analisis faktor pengaruh pemilihan lokasi industri dilakukan dengan analisis regresi linier berganda berdasarkan Metode Stepwise.

Variabel dependen (Y) yang digunakan mengacu pada penelitian Deichmann (2005) yaitu keuntungan sebagai fungsi karakteristik spesifik lokasi. Variabel independen yang digunakan yaitu kedekatan bahan baku (X1), kuantitas bahan baku (X2), upah tenaga kerja (X3), dan kedekatan pasar (X4). Rumus analisis regresi linier sederhana yang digunakan adalah sebagai berikut (Hadi, 1983).

Keterangan :

$$
\mathrm{Y}=\mathrm{K}+\mathrm{anXn}
$$

$\mathrm{Y}=$ Keuntungan

$\mathrm{K}=$ Bilangan konstan

an = Koefisien yang diperoleh dari perhitungan data

$\mathrm{Xn}=$ prediktor variabel independen $\left(\mathrm{X}_{1} ; \mathrm{X}_{2} ; \mathrm{X}_{3} ; \mathrm{X}_{4}\right)$

Untuk regresi linier berganda dapat menggunakan persamaan sebagai berikut.

$$
\mathrm{Y}=\mathrm{K}+\mathrm{a}_{1} \mathrm{X}_{1}+\mathrm{a}_{2} \mathrm{X}_{2}+\mathrm{a}_{3} \mathrm{X}_{3}+\mathrm{a}_{4} \mathrm{X}_{4}
$$

Keterangan :

$\mathrm{Y}=$ Keuntungan

$\mathrm{K}=$ Bilangan Kontan

an = Koefisien yang diperoleh dari perhitungan data

$\mathrm{X}_{1}=$ Kedekatan Bahan Baku

$\mathrm{X}_{2}=$ Kuantitas Bahan Baku

$\mathrm{X}_{3}=$ Upah Tenaga Kerja

$\mathrm{X}_{4}=$ Kedekatan Pasar

Sebagai syarat regresi linier berganda perlu dilakukan beberapa uji salah satunya uji normalitas. Jika distribusi tidak normal maka perlu untuk dilakukan transformasi data. Salah satu langkah yang bisa dilakukan adalah dengan menggunakan transformasi logaritma. 


\section{HASIL DAN PEMBAHASAN}

3.1. Persebaran Titik Sentra Industri Kerajinan Bambu di Kabupaten Sleman

Berdasarkan Gambar 1 dapat diketahui bahwa sentra-sentra industri kerajinan bambu Kabupaten Sleman terletak dan mengelompok di Sleman bagian barat. Sentra industri kerajinan bambu Kabupaten Sleman tersebar di Kecamatan Minggir, Moyudan, Godean, Seyegan, dan Mlati. Pengelompokkan di beberapa kecamatan tersebut dapat terjadi karena faktor-faktor tertentu.

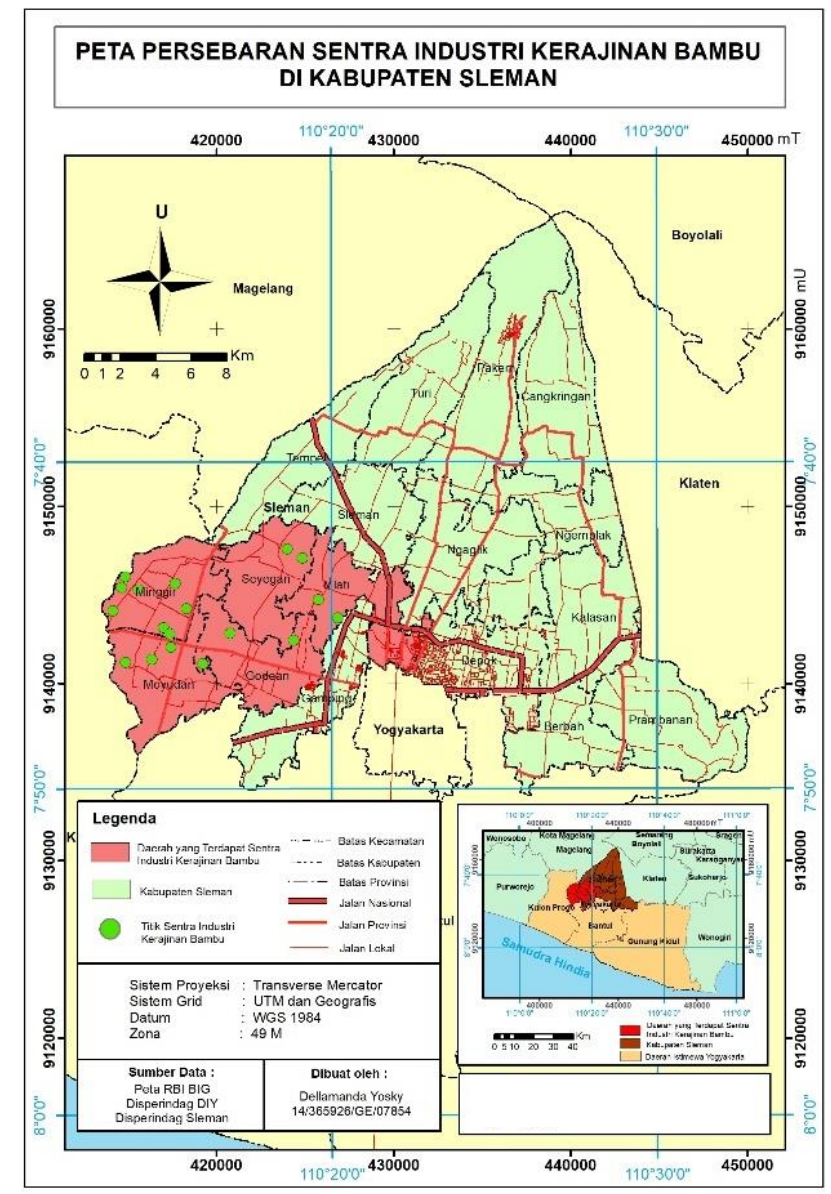

Gambar 1. Peta Persebaran Titik Sentra Industri Kerajinan Bambu di Kabupaten Sleman

Berdasarkan penelitian Swarsingkin (2015) mengenai industri kerajinan serat alam di Kabupaten Bantul dan Kulonprogo menjelaskan bahwa perkembangan industri serat alam memiliki korelasi dengan wilayah bahan baku, tenaga kerja, dan pasar. Faktor-faktor tersebut baik salah satu maupun semuanya berpotensi memiliki pengaruh terhadap berdiri serta berkembangnya suatu sentra industri. Berdasarkan observasi, berdiri dan berkembangnya industri kerajinan bambu di Kabupaten Sleman wilayah barat juga terkait dengan bahan baku, ketrampilan yang dimiliki penduduk setempat, serta tradisi.

Masing-masing sentra memiliki jenis hasil produk kerajinan bambu yang khas. Gambar 2 menunjukkan bahwa di Kecamatan Minggir terdapat sentra besek dan aneka kerajinan bambu, begitu pula di Kecamatan Moyudan. Di Kecamatan Godean terdapat sentra industri tambir, tumbu, anyaman kepang, dan tirai bambu. Di Kecamatan Seyegan terdapat sentra industri kerajinan bambu anyaman gedek dan mebel bambu. Hampir sama seperti Seyegan, Kecamatan Mlati juga memiliki sentra industri mebel bambu, serta anyaman berupa anyaman kepang bermotif. 
Yosky, Budiani/ Jurnal Pembangunan Wilayah dan Kota, Vol.15 No.4, 2019, 301-309

Doi: https://doi.org/10.14710/pwk.v15i4.20594

3.2. Karakteristik Usaha Industri Kerajinan Bambu di Kabupaten Sleman

Industri kerajinan bambu Kabupaten Sleman sebagian besar merupakan industri skala rumah tangga.

Namun demikian, terdapat beberapa sentra yang berskala industri kecil. Hal ini dapat dilihat berdasarkan data jumlah tenaga kerja yang bekerja pada industri sebagai berikut.

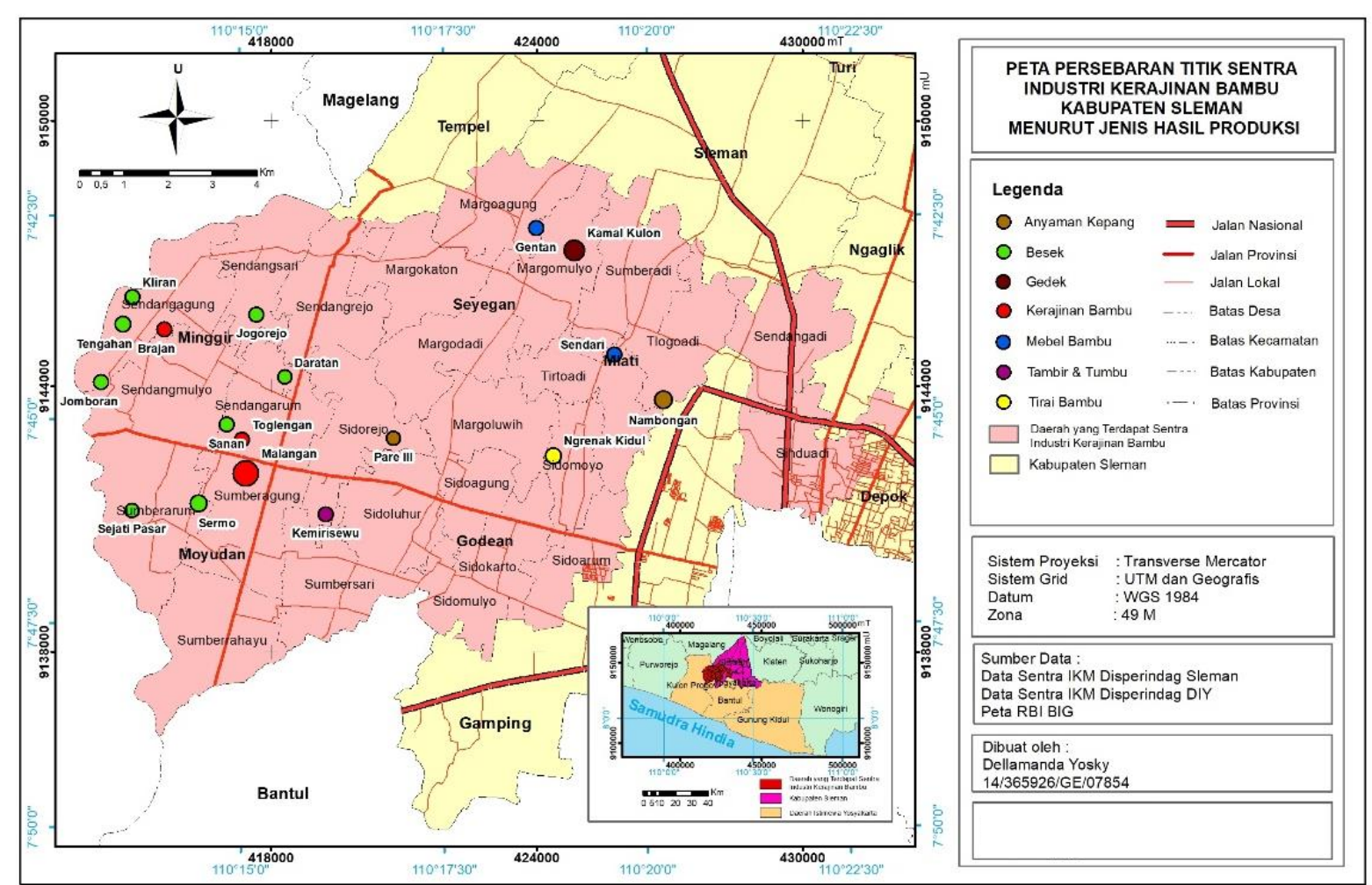

Gambar 2. Peta Persebaran Titik Sentra Industri Kerajinan Bambu di Kabupaten Sleman Menurut Jenis Hasil Produksi

Tabel 1. Jumlah Tenaga Kerja Industri Kerajinan Bambu di Kabupaten Sleman

\begin{tabular}{lll}
\hline Jumlah Tenaga Kerja & Frekuensi & Persentase (\%) \\
\hline Industri Rumah Tangga (1-4) & 80 & 92 \\
Industri Kecil (5-19) & 7 & 8 \\
Total & 87 & 100 \\
\hline
\end{tabular}

Sumber: Data Primer, 2018

Dalam proses produksi tidak semua unit usaha memiliki tenaga kerja karena banyaknya industri rumah tangga yang skala produksinya masih sangat kecil. Apabila mempunyai tenaga kerjapun biasanya berasal dari daerah sekitar sentra saja. Selain alasan jarak dan upah, pemilihan tenaga kerja dari daerah sekitar lokasi produksi adalah karena ketrampilan yang dimiliki biasanya telah memenuhi kriteria yang dibutuhkan.

Pelaku usaha industri bambu terdiri atas laki-laki dan perempuan. Namun secara keseluruhan didominasi oleh perempuan. Pelaku usaha laki-laki biasanya memiliki industri kerajinan bambu jenis mebel bambu, tirai, anyaman gedek, maupun aneka kerajinan, sedangkan perempuan biasanya membuat besek, anyaman kepang, tambir, tumbu, serta anyaman kecil lainnya. 
Yosky, Budiani/ Jurnal Pembangunan Wilayah dan Kota, Vol.15 No.4, 2019, 301-309 Doi: https://doi.org/10.14710/pwk.v15i4.20594

Tabel 2. Kedekatan Bahan Baku Industri Kerajinan Bambu di Kabupaten Sleman

\begin{tabular}{lll}
\hline Jarak Asal Bahan Baku (meter) & Frekuensi & Persentase (\%) \\
\hline Dekat (5-3333) & 80 & 92,0 \\
Sedang (3334-6666) & 4 & 4,6 \\
Jauh (6667-10000) & 3 & 3,4 \\
Total & 87 & 100 \\
\hline
\end{tabular}

Sumber: Data Primer, 2018

Bahan baku bambu banyak diambil di daerah Sleman bagian barat seperti di Kecamatan Minggir dan Moyudan bahkan dari Kabupaten Kulonprogo. Dapat dilihat pada Tabel 2 bahwa 92\% industri memperoleh bahan baku dalam radius kurang dari 3,3 km. Industri tersebut sebagian besar merupakan industri skala rumah tangga yang skala produksi masih terbatas sehingga kebutuhan akan bahan baku dapat dikatakan tidak terlalu banyak. Kebutuhan bambu yang tidak terlalu banyak ini dapat terpenuhi oleh ketersediaan bambu di daerah yang masih relatif dekat dengan lokasi produksi. Di sisi lain, industri yang lebih besar membutuhkan bahan baku dalam jumlah lebih banyak sehingga harus mencari bambu di daerah yang benarbenar banyak menghasilkan bambu.

Tabel 3. Nilai Bahan Baku 1 Bulan Terakhir Industri Kerajinan Bambu di Kabupaten Sleman

\begin{tabular}{lll}
\hline Nilai Bahan Baku (rupiah) & Frekuensi & Persentase (\%) \\
\hline $5000-200000$ & 63 & 72,4 \\
$210000-400000$ & 7 & 8 \\
$410000-600000$ & 3 & 3,4 \\
$610000-800000$ & 3 & 3,4 \\
$810000-1000000$ & 0 & 0 \\
$>1000000$ & 11 & 12,6 \\
Total & 87 & 100 \\
\hline
\end{tabular}

Sumber: Data Primer, 2018

Kuantitas bahan baku bambu yang dibutuhkan dapat dilihat pada Tabel 3. Semakin banyak bambu yang dibutuhkan tentu biaya yang dikeluarkan sebagai modal menjadi lebih besar. Hal ini sesuai dengan penelitian Syarif (2012) yang menjelaskan bahwa modal berpengaruh positif terhadap jumlah produksi. Data menunjukkan 72,4\% industri membutuhkan bambu dengan nilai berkisar antara Rp 5.000,00 - Rp 200.000,00 dalam sekali produksi. Hal ini membuktikan bahwa terdapat industri kerajinan bambu yang masih berskala produksi sangat kecil. Akan tetapi ada pula industri yang sudah lebih berkembang, bahkan sudah berkembang sehingga memiliki pasar yang luas. Hal ini berbanding lurus dengan hasil perhitungan keuntungan bersih yang didapat para pelaku usaha kerajinan bambu Kabupaten Sleman yang rata-rata sebesar Rp 823.000,00. Dapat dilihat pada Tabel 4 bahwa 89,7\% industri memilki keuntungan yang rendah, $5,7 \%$ memiliki keuntungan sedang, dan 4,6\% memiliki keuntungan yang tinggi.

Tabel 4. Keuntungan 1 Bulan Terakhir Pelaku Usaha Industri Kerajinan Bambu di Kabupaten Sleman

\begin{tabular}{lll}
\hline Keuntungan Usaha (rupiah) & Frekuensi & Persentase (\%) \\
\hline Rendah (0-2300000) & 78 & 89,7 \\
Sedang (2400000-4700000) & 5 & 5,7 \\
Tinggi (4800000-7000000) & 4 & 4,6 \\
Total & 87 & 100 \\
Rata-rata & 823.000 & \\
\hline
\end{tabular}

Sumber: Data Primer, 2018

Faktor pasar menurut Holmes \& Steven (2003) mempengaruhi pemilihan lokasi suatu pabrik. Adanya sentra memudahkan dalam pemasaran karena proses jual-beli menjadi terpusat di sentra tersebut. Konsumen juga akan lebih mudah dalam mendapatkan barang yang diinginkan. Jangkauan pemasaran dapat 
diperluas dengan promosi dan penjualan secara online. Namun, belum banyak pelaku usaha industri yang menggunakan cara ini. Bahkan masih banyak pula industri-industri rumah tangga yang mengandalkan pengepul setempat sehingga cakupan pemasaran dapat dikatakan masih terbatas. Padahal cakupan pemasaran semakin luas maka potensi keuntungan lebih besar dapat diperoleh. Dapat dilihat pada Tabel 5 bahwa cakupan pasar terbanyak sebesar $62,1 \%$ adalah cakupan wilayah satu desa. Biasanya perajin akan memasarkan hasil produsinya kepada pengepul setempat.

Tabel 5. Cakupan Daerah Pemasaran Terluas Industri Kerajinan Bambu di Kabupaten Sleman

\begin{tabular}{lll}
\hline Cakupan Daerah Pemasaran & Frekuensi & Persentase (\%) \\
\hline Satu Desa & 54 & 62,1 \\
Satu Kecamatan & 11 & 12,6 \\
Satu Kabupaten & 6 & 6,9 \\
Satu Provinsi & 10 & 11,5 \\
Nasional & 5 & 5,7 \\
Internasional & 1 & 1,1 \\
Total & 87 & 100 \\
\hline
\end{tabular}

Sumber: Data Primer, 2018

Menurut Sari (2018) dalam penelitiannya mengenai industri tenun Gamplong, strategi pemasaran yang sesuai untuk industri tersebut adalah strategi menjaga dan mempertahankan. Hal ini juga penting dilakukan untuk industri kerajinan bambu di Kabupaten Sleman. Inovasi perlu terus dilakukan agar hasil produksi dapat bersaing dengan produk-produk lain yang mempunyai fungsi serupa.

3.3. Faktor-faktor Pemilihan Lokasi yang Berpengaruh terhadap Keuntungan sebagai Fungsi Karakteristik Lokasi

Hasil perhitungan regresi linier berganda menunjukkan angka $R$ sebesar 0,837 yang berarti terdapat hubungan yang kuat antara faktor-faktor pemilihan lokasi dengan keuntungan karena angka tersebut yang mendekati 1. Besar koefisien determinasi sebesar 0,700 yang berarti pengaruh faktor-faktor lokasi terhadap keuntungan sebesar 70\%, sedangkan 30\% dipengaruhi oleh faktor-faktor lainnya.

Nilai $F$ yang didapat sebesar 98,020 sedangkan besar signifikansinya sebesar 0,000 lebih kecil dari 0,05 maka Ho ditolak, Ha diterima. Dengan demikian, dapat dikatakan bahwa variabel independen dapat menjelaskan variasi nilai dependen. Artinya, faktor-faktor pemilihan lokasi dapat memprediksi variabel keuntungan.

Hasil perhitungan regresi linier berganda berdasarkan Metode Stepwise menunjukkan hasil persamaan sebagai berikut.

Keterangan :

$$
\log Y=3,339+0,516\left(\log X_{2}\right)-0,169\left(\log X_{4}\right)
$$

$\mathrm{Y}=$ Keuntungan

$\mathrm{X} 2=$ Kuantitas Bahan Baku

$\mathrm{X}_{4}=$ Kedekatan Pasar

Berdasarkan hasil regresi linier berganda di atas dapat diketahui hubungan antara masing-masing faktor lokasi dengan keuntungan. Metode Stepwise pada analisis regresi berganda mampu mengeliminasi variabel independen yang tidak berpengaruh signifikan. Variabel yang tidak berpengaruh signifikan tersebut akan tereliminasi dari persamaan yang diperoleh. Hasil regresi linier berganda menunjukkan variabel yang tidak tereliminasi adalah kauntitas bahan baku dan kedekatan pasar. Tanda positif pada koefisien regresi kuantitas bahan baku menunjukkan hubungan positif terhadap keuntungan. Di samping itu, koefisien regresi kedekatan pasar bertanda negatif berarti memiliki hubungan negatif dengan keuntungan. Namun, secara bersama-sama keseluruhan faktor pemilihan lokasi memiliki hubungan positif dengan keuntungan dengan nilai constant sebesar 3,339. 
Signifikan-tidaknya pengaruh masing-masing faktor pemilihan lokasi terhadap keuntungan dapat dilihat berdasarkan nilai signifikansi t tes. Faktor kuantitas bahan baku memiliki nilai t tes sebesar 9,965 dengan nilai signifikansi sebesar 0,000. Nilai signifikansi kurang dari 0,05 artinya pengaruh kuantitas bahan baku dan keuntungan signifikan atau terdapat pengaruh kuantitas bahan baku terhadap keuntungan. Faktor kedekatan pasar memiliki nilai t tes sebesar -3,296 dengan nilai signifikansi sebesar 0,001. Nilai signifikansi lebih kecil dari 0,05 yang berarti pengaruh kedekatan pasar dengan keuntungan signifikan atau terdapat pengaruh antara kedekatan pasar terhadap keuntungan.

Berdasarkan hasil regresi secara keseluruhan dapat diambil kesimpulan bahwa dari keempat faktor pemilihan lokasi yang diteliti yaitu kedekatan bahan baku, kuantitas bahan baku, upah tenaga kerja, dan kedekatan pasar, faktor yang paling berpengaruh terhadap keuntungan sebagai fungsi karakteristik spesifik lokasi adalah kuantitas bahan baku. Kuantitas bahan baku memiliki pengaruh paling kuat karena berbanding lurus pula dengan skala industri. Kuantitas bahan baku semakin banyak dibutuhkan biasanya skala industri juga semakin besar yang berarti produksinya semakin banyak. Dengan demikian keuntungan bersih yang didapat juga lebih besar. Dalam hal ini jarak asal bahan baku dapat dikatakan bukan lagi menjadi masalah bagi industri kerajinan bambu Kabupaten Sleman. Kondisi ini cukup berbeda dengan hasil penelitian industri gula kelapa di wilayah Kecamatan Nglegok, Blitar (Sudarsono, 2014) yang menjelaskan bahwa kedekatan bahan baku merupakan salah satu variabel yang menentukan lokasi sentra industri tersebut. Hal ini juga menguatkan jika perbedaan jenis industri juga akan mempengaruhi jenis variabel yang mempengaruhi penentuan lokasinya. Contoh lain yaitu hasil penelitian industri kerajinan serat alam di Kabupaten Bantul dan Kulonprogo (Swarsingkin, 2015) yang menyebutkan bahwa pengelompokkan industri di wilayah tersebut disebabkan kedekatan dengan tenaga kerja, sedangkan industri kerajinan bambu Kabupaten Sleman tidak begitu dipengaruhi tenaga kerja. Hal ini karena skala industrinya yang masih merupakan industri skala rumah tangga sehingga cukup banyak pelaku usaha yang tidak memiliki tenaga kerja, khususnya tenaga kerja upah.

\section{KESIMPULAN}

Sentra industri kerajinan bambu Kabupaten Sleman mengelompok di Kabupaten Sleman bagian barat dengan masing-masing sentra memiliki produk khas, yaitu: sentra besek dan aneka kerajinan berada di Kecamatan Minggir dan Moyudan; sentra tumbu, tambir, anyaman kepang, dan tirai bambu terletak di Kecamatan Godean; sedangkan sentra gedek, anyaman kepang bermotif, dan mebel bambu terletak di Kecamatan Seyegan dan Mlati. Sebagian besar industri kerajinan bambu Kabupaten Sleman merupakan industri skala rumah tangga dengan perolehan keuntungan sebagian besar di bawah Rp 2.300.000,00 tiap bulan.Faktor pemilihan lokasi yang paling berpengaruh terhadap keuntungan sebagai fungsi karakteristik spesifik lokasi adalah kuantitas bahan baku.

\section{SARAN}

Penelitian ini dilakukan secara kuantitatif sehingga perlu dikembangkan untuk penelitian secara kualitatif agar determinan pemilihan lokasi dapat dijelaskan dengan lebih rinci dan jelas, serta memperhatikan jalannya industri dari dulu hingga sekarang. Hal ini untuk lebih mengungkapkan alasan serta harapan para pelaku usaha kedepan demi keberlangsungan industri kerajinan bambu di Kabupaten Sleman.

\section{REFERENSI}

Bale, J. (1981). The Location of Manufacturing Industry: An Introduction Approach. Edinburgh: Oliver\&Boyd. BPS. (2016). Kabupaten Sleman Dalam Angka 2016. Sleman: BPS.

Deichmann, U., Kaiser, K., Lall, S. V., \& Shalizi, Z. (2005). Agglomeration, Transport, and Regional Development in Indonesia. World Bank Policy Research Working Paper 3477.

Dinas Perindustrian dan Perdagangan Kabupaten Sleman. (2015). Profil Sentra Industri Sleman. Sleman: Dinas Perindustrian dan Perdagangan Sleman

Dinas Koperasi dan UKM. (2016). Data UMKM Kabupaten Sleman Tahun 2016. Sleman: Dinas Koperasi dan UKM

Dinas Perindustrian Perdagangan DIY. (2017). Potensi IKM DIY Tahun 2017 Yogyakarta: Dinas Perindustrian Perdagangan DIY. 
Yosky, Budiani/ Jurnal Pembangunan Wilayah dan Kota, Vol.15 No.4, 2019, 301-309

Doi: https://doi.org/10.14710/pwk.v15i4.20594

Hadi, S. (1983). Analisis Regresi. Yogyakarta: Andi Offset.

Holmes, T. J., \& Stevens, J. J. (2003). Spatial Distribution of Economic Activities in North America. University of Minnesota and Federal Reserve Bank of Minneapolis and National Bureau of Economic Research.

Kantor Desa Sendangsari. (2015). Industri Kecil yang Sudah Terdata Tahun 2015. Desa Sendangsari Kecamatan Minggir.

Muzayanah. (2015). Terapan Teori Lokasi Industri (Contoh Kasus Pengembangan Kawasan Industri Kragilan Kabupaten Serang). Jurnal Geografi: Geografi dan Pengajarannya Volume 13 Nomor 2 Desember 2015.

Pemerintah Kabupaten Sleman. (2013). Bambu Menjadi Komoditas Unggulan Sleman. (http://www.slemankab.go.id/ diakses tanggal 19 Juli 2017).

Sari, R. I., \& Budiani, S. R. (2018). Analisis Strategi Pemasaran Industri Tenun di Desa Wisata Gamplong Kabupaten Sleman. Majalah Geografi Indonesia, Volume 32, Nomor 1, Maret 2018.

Sudarsono, F. G. (2014). Faktor-faktor Penentu Lokasi Sentra Industri Gula Kelapa (Studi Kasus: di Wilayah Kecamatan Nglegok, Kabupaten Blitar). Jurnal Ilmiah. Malang: Universitas Brawijaya.

Sugiyono. (2011). Metode Penelitian Kuantitatif, Kualitatif, dan R\&B. Bandung: Alfabeta.

Syarif, A., \& Harini, R. (2012). Industri Genteng di Desa Sidoluhur Kecamatan Godean Kabupaten Sleman. Jurnal Bumi Indonesia Volume 1, Nomor 1, Tahun 2012.

Swarsingkin, N. H., \& Budiani, S. R. (2015). Studi Komparatif Industri Kerajinan Serta Alam Kabupaten Bantul dan Kabupaten Kulonprogo. Jurnal Bumi Indonesia, Volume 4, Nomor 1, Tahun 2015. 